\title{
Radiative lifetime measurements and oscillator strengths of astrophysical interest in Ho III
}

\author{
Z. G. Zhang ${ }^{1}$, G. Somesfalean ${ }^{1}$, S. Svanberg ${ }^{1}$, P. Palmeri ${ }^{2}$, P. Quinet ${ }^{2,3}$, and E. Biémont ${ }^{2,3}$ \\ 1 Department of Physics, Lund Institute of Technology, PO Box 118, 22100 Lund, Sweden \\ 2 Astrophysique et Spectroscopie, Université de Mons-Hainaut, 7000 Mons, Belgium \\ 3 IPNAS, Bât. B15, Université de Liège, Sart Tilman, 4000 Liège, Belgium
}

Received 26 July 2001 / Accepted 14 December 2001

\begin{abstract}
Radiative lifetimes of three long-lived levels belonging to the $4 \mathrm{f}^{10} 5 \mathrm{~d}$ configuration of Ho III have been measured, for the first time, using the time-resolved laser-induced fluorescence technique. A good agreement between the experimental lifetimes and theoretical results obtained within a multiconfigurational pseudo-relativistic Hartree-Fock (HFR) approach including core-polarization (CP) effects is observed provided an adequate scaling factor is applied to the $<4 \mathrm{f}|\mathrm{r}| 5 \mathrm{~d}>$ transition matrix element. From the comparison theory-experiment, it has been possible to assess the reliability of the oscillator strengths of the $4 \mathrm{f}-5 \mathrm{~d}$ transitions of astrophysical interest, particularly for the lines depopulating the levels considered in the present work. The present results fill in a gap concerning the $f$-values of doubly ionized holmium and are needed for a quantitative evaluation of the holmium abundance in some peculiar stars.
\end{abstract}

Key words. atomic data - atomic processes - stars: chemically peculiar

\section{Introduction}

In most chemically peculiar $(\mathrm{CP})$ stars, large overabundances of lanthanide elements are observed when compared to the solar standards. For the investigation of the chemical composition of the stars, the oscillator strengths are frequently the key parameters and accurate values are needed. The studies of nucleosynthesis of the heavy elements in the stars are also dependent upon accurate atomic data, particularly for rare earth (RE) ions. This need for accurate transition probabilities or $f$-values, frequently pointed out in astrophysics, has stimulated a variety of radiative lifetime measurements in neutral or singly ionized lanthanide atoms (Blagoev \& Komarovskii 1994). However, according to the Saha equation, it is expected that the lanthanide elements are predominantly doubly ionized in the photosphere of the hotter CP stars (Aikman et al. 1979). The very acute need for reliable atomic data in doubly ionized $\mathrm{RE}$ atoms has stimulated recent studies of the third lanthanide spectra by laser spectroscopy and also elaborate theoretical calculations (Zhang et al. 2000, 2001a-c; Wyart et al. 1997; Biémont et al. 1999, 2001a-c; Bord et al. 1997; Wyart \& Palmeri 1998; Palmeri et al. 2001; Li et al. 2001; Li \& Jiang 1999; Wahlgren et al. 2001; Fedchak et al. 2000; Li et al. 2000). In particular, the

Send offprint requests to: E. Biémont, e-mail: E.Biemont@ulg.ac.be combination of lifetime measurements carried out in the VUV laboratory of the Lund Laser Centre (Sweden) with theoretical calculations carried out at Liège and Mons universities (Belgium) has allowed to obtain reliable data for over 50000 transitions belonging to the RE ions. For more details, see the database D.R.E.A.M at the following address: http://www. umh.ac.be/ astro/dream.shtml

Transition probability determination or radiative lifetime measurements in Ho I have been the subject of only a very limited number of investigations (Corliss \& Bozman 1962; Blagoev et al. 1978; Gorshkov \& Komarovskii 1979; Doidge 1995a,b; 1996). The situation is similar in Ho II where only scarse measurements are available (Gorshkov \& Komarovskii 1979; Worm et al. 1990; Den Hartog et al. 1999). The only calculations in the latter ion have been performed by Migdalek (1984). In Ho III, no transition probabilities at all were available, up to very recently, either on the theoretical or on the experimental side. In a very recent work however (Biémont et al. 2001d), lifetimes of six levels belonging to the $4 \mathrm{f}^{10} 6 \mathrm{p}$ configuration of Ho III have been measured for the first time using a time-resolved laser-induced fluorescence technique. A very good agreement has been achieved with theoretical pseudo-relativistic HFR calculations. Using the experimental lifetimes and theoretical branching fractions, a first set of $f$-values concerning transitions of the types $5 \mathrm{~d}-6 \mathrm{p}$ or $6 \mathrm{~s}-6 \mathrm{p}$ has been proposed for this ion. 
Table 1. Ho III levels measured and the corresponding excitation schemes.

\begin{tabular}{lccccc}
\hline Levels $^{a}$ & \multicolumn{2}{c}{ Energy $\left(\mathrm{cm}^{-1}\right)$} & \multicolumn{2}{c}{ Excitation } & \multicolumn{2}{c}{ Laser } \\
& Lower & Upper & $\lambda_{\text {air }}(\mathrm{nm})$ & mode $^{b}$ & $\lambda_{\text {air }}(\mathrm{nm})$ \\
\hline $4 \mathrm{f}^{10}\left({ }^{5} \mathrm{I}_{7}\right) 5 \mathrm{~d}_{5 / 2}(7,5 / 2)_{15 / 2}$ & 0.0 & 27074.39 & 369.248 & $2 \omega+S$ & 369.2 \\
$4 \mathrm{f}^{10}\left({ }^{5} \mathrm{I}_{8}\right) 5 \mathrm{~d}_{5 / 2}(8,5 / 2)_{13 / 2}$ & 0.0 & 27913.71 & 358.145 & $2 \omega+S$ & 358.1 \\
$4 \mathrm{f}^{10}\left({ }^{5} \mathrm{I}_{6}\right) 5 \mathrm{~d}_{5 / 2}(6,5 / 2)_{13 / 2}$ & 0.0 & 31903.06 & 313.359 & $2 \omega$ & 313.4 \\
\hline
\end{tabular}

a From Martin et al. (1978).

${ }^{b} 2 \omega$ means frequency-doubling and $S$ is written for Stokes component.

The present work is motivated by the need of accurate atomic oscillator strengths, particularly for the $4 \mathrm{f}-5 \mathrm{~d}$ transitions of Ho III which are necessary for a quantitative analysis of the chemical composition of some CP stars. These transitions have been identified in a number of stellar spectra e.g. in the silicon Ap star HD 192913 (Adelman et al. 1979; Cowley \& Crosswhite 1978; Ryabchikova et al. 1990) or in the CP star HR 465 (Bidelman et al. 1995). Some of the resonance transitions are emitted from the three levels at $31903.06,27913.71$ and $27074.39 \mathrm{~cm}^{-1}$ belonging to the $4 \mathrm{f}^{10} 5 \mathrm{~d}$ configuration for which lifetimes have been measured in the present work.

\section{Experimental measurements}

In the present experiment, the lifetimes of three $5 \mathrm{~d}$ Ho III levels were measured using one-step excitation with a time-resolved laser-induced fluorescence technique. The experimental schemes followed for the measurements are summarized in Table 1.

The experimental set-up considered in the experiment is shown in Fig. 1. It is similar to the one used in recent lifetime measurements of Nd III (Zhang et al. 2001a). In order to obtain the required excitation light, the $532 \mathrm{~nm}$ wavelength emitted from an injected seeder Nd:YAG laser (Continuum NY-82) with a pulse duration of $8 \mathrm{~ns}$, a repetition rate of $10 \mathrm{~Hz}$ and a single pulse energy of $400 \mathrm{~mJ}$ was sent to a Stimulated Brillouin Scattering (SBS) compressor to shorten the pulses. The pulse duration of the output from the SBS compressor was about $1 \mathrm{~ns}$, and the single pulse energy was about $200 \mathrm{~mJ}$. The short pulse was used to pump a dye laser (Continuum Nd-60) in which a DCM dye was run. The dye laser was frequency doubled in a KDP crystal. The second harmonic from the KDP crystal was used to excite the $\mathrm{Ho}^{2+}$ ions from the ground state to the level at $31903.06 \mathrm{~cm}^{-1}$. The other two levels were excited by the first-order Stokes stimulated Raman scattering (SRS) of the second harmonic. The SRS was produced by focusing the second harmonic into a hydrogen cell with 10 bars pressure. The excitation laser was selected using a quartz Pellin-Broca prism and it was focused by two quartz lenses at the centre of a vacuum chamber, about $10 \mathrm{~mm}$ above a pure Ho rotated foil.

In the experiments, free $\mathrm{Ho}^{2+}$ ions were obtained from a laser-induced plasma. Laser pulses, characterized by a $532 \mathrm{~nm}$ wavelength, a $10 \mathrm{~Hz}$ repetition rate and a $10 \mathrm{~ns}$

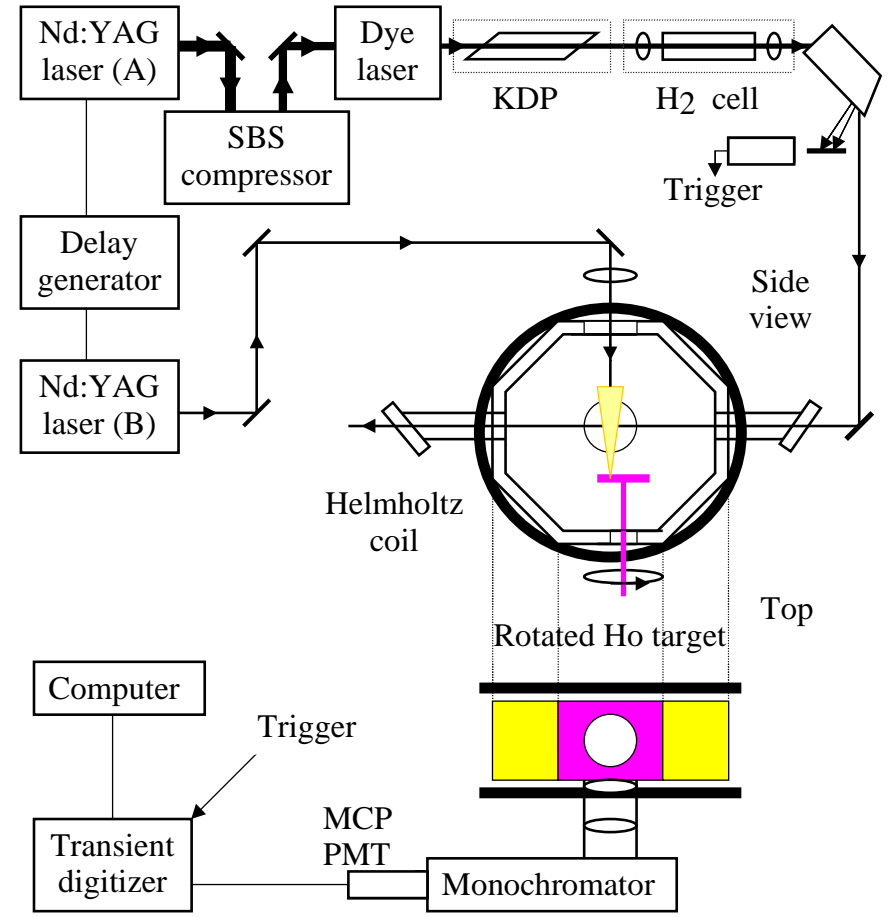

Fig. 1. Experimental set-up used for the lifetime measurements.

duration, emitted from another Nd:YAG laser (Continuum Surelite) with 0-50 mJ tunable pulse energy, were focused vertically onto the surface of the Ho foil in the vacuum chamber. After the laser pulse, the plasma expanded from the foil. In the plasma, atoms and ions in different ionization stages are moving with different speeds. When $\mathrm{Ho}^{2+}$ ions reached the interaction zone, $10 \mathrm{~mm}$ above the foil, the ions were excited by the excitation laser passing through the plasma horizontally. These were performed by using a digital delay generator (Stanford Research System Model 535) to trigger the two Nd:YAG lasers externally because the delay generator can be used to adjust the delay time between the ablation and excitation pulses. In the measurements, the decay fluorescence from the level measured was imaged by two $\mathrm{CaF}_{2}$ lenses onto the entrance slit of a vacuum monochromator, and detected by a Hamamatsu R3809U-38 photomultiplier. The time-resolved signal was acquired and averaged using a digital transient recorder (Tektronix Model DSA 602). 
Table 2. Radiative lifetimes for $4 \mathrm{f}^{10} 5 \mathrm{~d}$ levels in Ho III (in ns).

\begin{tabular}{lcccc}
\hline Level & $E\left(\mathrm{~cm}^{-1}\right)^{a}$ & & $\tau(\mathrm{ns})$ \\
HFR+CP* & Expt \\
\hline $4 \mathrm{f}^{10}\left({ }^{5} \mathrm{I}_{7}\right) 5 \mathrm{~d}_{5 / 2}(7,5 / 2)_{15 / 2}$ & 27074.39 & 260 & 167 & $186 \pm 20$ \\
$4 \mathrm{f}^{10}\left({ }^{5} \mathrm{I}_{8}\right) 5 \mathrm{~d}_{5 / 2}(8,5 / 2)_{13 / 2}$ & 27913.71 & 227 & 145 & $125 \pm 15$ \\
$4 \mathrm{f}^{10}\left({ }^{5} \mathrm{I}_{6}\right) 5 \mathrm{~d}_{5 / 2}(6,5 / 2)_{13 / 2}$ & 31903.06 & 161 & 103 & $105 \pm 15$ \\
\hline
\end{tabular}

a From Martin et al. (1978).

HFR: this work.

$\mathrm{HFR}+\mathrm{CP}$ (core-polarization included): this work.

* Obtained with the $<4 \mathrm{f}|\mathrm{r}| 5 \mathrm{~d}>$ dipole matrix element multiplied by 1.27 (see text).

The averaged time-resolved fluorescence decay curve was sent to a personal computer for lifetime evaluation.

In the measurements, it was carefully verified that the correct level was excited by checking whether the additional transitions in the spectral neighbourhood of the excitation wavelength were excited and by observing at which delay time the fluorescence signal was maximum. Usually, the maximum signal occurred at a delay time of about $1.2 \mu \mathrm{s}$ for Ho III, and at about $2 \mu \mathrm{s}$ for Ho II. The maximum for neutral holmium is expected to occur even later. A background signal was superimposed on the fluorescence. It originated mainly from the recombination between ions with electrons in the plasma (Zhang et al. 2001c).

The recombination can reduce the number of ions in such a way that the lifetimes measured become too short. A suitable magnetic field, about 70 Gauss, was added in the plasma zone by a pair of Helmholtz coils in order to eliminate possible Zeeman quantum beat effects but also to weaken the background associated with the ablation laser and the plasma recombination processes. Although the mechanism of the effect of the field is not clearly understood, the field was very important and effective for removing the background light when performing lifetime measurements in doubly-ionized ions. This is probably related to the fact that both the electrons and the ions, forming the background light during the recombination process, move very fastly under the action of the applied field.

In order to effectively collect the fluorescence, the entrance slit of the monochromator was placed horizontally and it was opened maximally (up to a width of $5 \mathrm{~mm}$ ). However, this was not sufficient to avoid flight-out-of-view effects. The maximum fluorescence signal corresponds to the distribution of high speed of the ions. We then increased the delay time so that the collected fluorescence signal was emitted from ions with lower speed. Increasing the delay time made the signal weaker. Sometimes only one photon was acquired for one pulse. In order to get a reasonable signal-to-noise ratio, a fluorescence decay curve was obtained by averaging fluorescence photons from more than 4000 pulses.

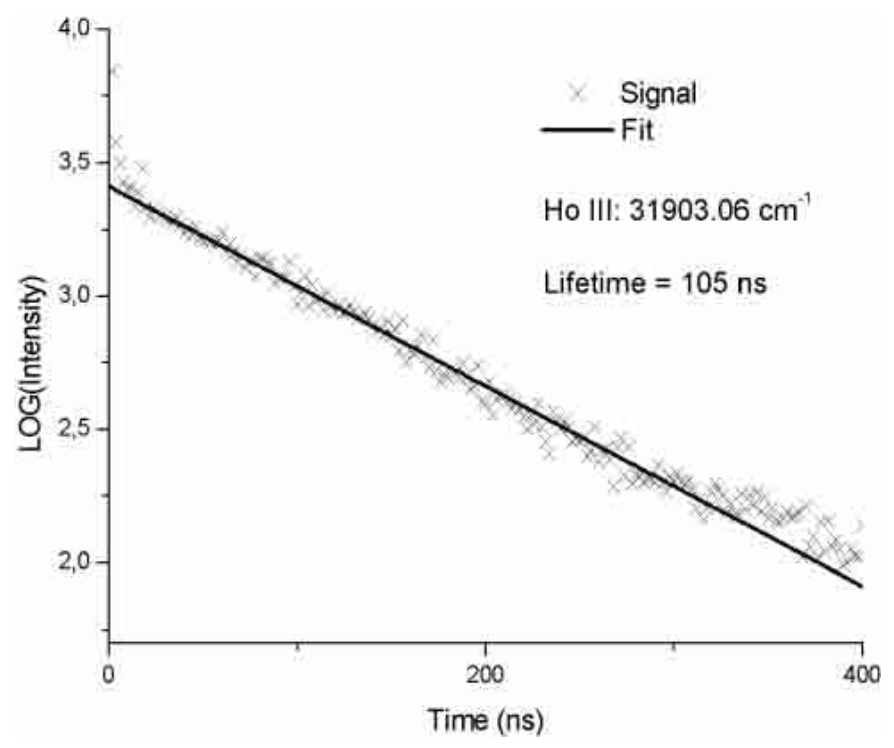

Fig. 2. A typical experimental time-resolved fluorescence signal from the long lived level at $31903.06 \mathrm{~cm}^{-1}$ in Ho III. The lifetime deduced from the fit was 105 ns.

During the experiments, a variety of experimental conditions were modified, including the delay time, the intensity of the excitation laser and also that of the ablation laser. This resulted in a change of the fluorescence signal by a factor of 10 . However, it was found that the lifetime values had no clear systematic trend. The lifetime evaluation was performed by an exponential fit, and the lifetime value was obtained through the averaging of about 10 curves for each level. A typical curve and the corresponding fit are shown in Fig. 2, and the three lifetimes measured are given in Table 2 , where the quoted uncertainties reflect not only the statistical errors, but also possible small remaining systematic errors.

\section{Theoretical calculations and applications}

The theoretical procedure used in the present work has been described previously (Biémont et al. 2001d) and a brief summary only is reported here. Configuration interaction was considered between $4 \mathrm{f}^{11}, 4 \mathrm{f}^{10} 6 \mathrm{p}, 4 \mathrm{f}^{10} 7 \mathrm{p}, 4 \mathrm{f}^{10} 5 \mathrm{f}$ 
Table 3. Theoretical oscillator strengths and radiative transition probabilities for $4 \mathrm{f}^{11}-4 \mathrm{f}^{10} 5 \mathrm{~d}$ Ho III lines of astrophysical interet. Only the transitions originating from a lower level with $E<22000 \mathrm{~cm}^{-1}$ and for which $\log g f>-2.50$ are quoted.

\begin{tabular}{|c|c|c|c|c|c|c|c|c|}
\hline \multirow[b]{2}{*}{$\lambda(\mathrm{nm})$} & \multicolumn{4}{|c|}{ Levels $\left(\mathrm{cm}^{-1}\right)^{a}$} & \multirow[b]{2}{*}{$\log g f^{b}$} & \multirow[b]{2}{*}{$g A^{b}$} & \multirow[b]{2}{*}{$\mathrm{CF}^{*}$} & \multirow[b]{2}{*}{ Note } \\
\hline & Lower & $J$ & Upper & $J$ & & & & \\
\hline 234.5216 & $0(\mathrm{o})$ & 7.5 & 42627 (e) & 6.5 & -1.66 & $2.67 \mathrm{E}+07$ & -0.044 & \\
\hline 253.8065 & $0(\mathrm{o})$ & 7.5 & $39388(\mathrm{e})$ & 6.5 & -1.37 & $4.35 \mathrm{E}+07$ & 0.157 & \\
\hline 259.3158 & $0(\mathrm{o})$ & 7.5 & $38551(\mathrm{e})$ & 6.5 & -1.36 & $4.27 \mathrm{E}+07$ & 0.079 & \\
\hline 287.6049 & $0(\mathrm{o})$ & 7.5 & $34760(\mathrm{e})$ & 6.5 & -1.52 & $2.42 \mathrm{E}+07$ & 0.105 & \\
\hline 288.3798 & $0(\mathrm{o})$ & 7.5 & $34666(\mathrm{e})$ & 7.5 & -2.26 & $4.39 \mathrm{E}+06$ & -0.165 & \\
\hline 293.4534 & $0(\mathrm{o})$ & 7.5 & 34067 (e) & 6.5 & -2.22 & $4.64 \mathrm{E}+06$ & -0.019 & \\
\hline 294.1844 & $8645(\mathrm{o})$ & 5.5 & $42627(\mathrm{e})$ & 6.5 & -2.45 & $2.75 \mathrm{E}+06$ & -0.110 & \\
\hline 313.3587 & $0(\mathrm{o})$ & 7.5 & $31903(\mathrm{e})$ & 6.5 & -1.02 & $6.50 \mathrm{E}+07$ & -0.281 & \\
\hline 315.2875 & $0(\mathrm{o})$ & 7.5 & $31708(\mathrm{e})$ & 8.5 & -2.40 & $2.70 \mathrm{E}+06$ & -0.460 & \\
\hline 320.7359 & $5439(\mathrm{o})$ & 6.5 & $36608(\mathrm{e})$ & 5.5 & -1.70 & $1.30 \mathrm{E}+07$ & -0.161 & \\
\hline 320.9323 & $0(\mathrm{o})$ & 7.5 & $31150(\mathrm{e})$ & 7.5 & -1.20 & $4.07 \mathrm{E}+07$ & -0.360 & \\
\hline 335.8655 & 5439 (о) & 6.5 & $35204(\mathrm{e})$ & 5.5 & -1.03 & $5.42 \mathrm{E}+07$ & -0.303 & \\
\hline 340.9525 & 5439 (o) & 6.5 & $34760(\mathrm{e})$ & 6.5 & -1.53 & $1.68 \mathrm{E}+07$ & 0.127 & $B$ \\
\hline 342.8070 & $0(\mathrm{o})$ & 7.5 & $29163(\mathrm{e})$ & 7.5 & -1.74 & $1.02 \mathrm{E}+07$ & -0.309 & \\
\hline 343.5270 & 8645 (o) & 5.5 & $37746(\mathrm{e})$ & 4.5 & -0.97 & $6.01 \mathrm{E}+07$ & -0.301 & \\
\hline 349.2028 & 5439 (o) & 6.5 & 34067 (e) & 6.5 & -1.49 & $1.76 \mathrm{E}+07$ & -0.187 & \\
\hline 354.4367 & 5439 (о) & 6.5 & $33644(\mathrm{e})$ & 5.5 & -1.64 & $1.19 \mathrm{E}+07$ & 0.178 & \\
\hline 357.5104 & 8645 (o) & 5.5 & $36608(\mathrm{e})$ & 5.5 & -1.37 & $2.26 \mathrm{E}+07$ & -0.172 & \\
\hline 358.1447 & $0(\mathrm{o})$ & 7.5 & $27914(\mathrm{e})$ & 6.5 & -0.89 & $6.80 \mathrm{E}+07$ & -0.248 & $B$ \\
\hline 358.1973 & $10770(\mathrm{o})$ & 4.5 & $38680(\mathrm{e})$ & 3.5 & -1.07 & $4.47 \mathrm{E}+07$ & -0.261 & \\
\hline 366.7299 & $0(\mathrm{o})$ & 7.5 & 27260 (e) & 8.5 & -1.90 & $6.25 \mathrm{E}+06$ & 0.439 & \\
\hline 367.1064 & 8645 (o) & 5.5 & 35877 (e) & 5.5 & -2.28 & $2.63 \mathrm{E}+06$ & -0.054 & \\
\hline 367.8363 & 8645 (o) & 5.5 & $35823(\mathrm{e})$ & 4.5 & -1.37 & $2.09 \mathrm{E}+07$ & -0.115 & \\
\hline 369.2476 & $0(\mathrm{o})$ & 7.5 & $27074(\mathrm{e})$ & 7.5 & -0.76 & $8.47 \mathrm{E}+07$ & -0.368 & $B$ \\
\hline 370.5994 & $10770(\mathrm{o})$ & 4.5 & $37746(\mathrm{e})$ & 4.5 & -1.13 & $3.59 \mathrm{E}+07$ & -0.157 & \\
\hline 371.4951 & 5439 (о) & 6.5 & 32349 (e) & 5.5 & -1.28 & $2.55 \mathrm{E}+07$ & -0.132 & $B$ \\
\hline 376.4103 & 8645 (o) & 5.5 & $35204(\mathrm{e})$ & 5.5 & -1.12 & $3.51 \mathrm{E}+07$ & -0.144 & $B$ \\
\hline 377.7569 & 5439 (о) & 6.5 & $31903(\mathrm{e})$ & 6.5 & -0.90 & $5.83 \mathrm{E}+07$ & -0.201 & $B$ \\
\hline 382.8112 & 8645 (o) & 5.5 & 34760 (e) & 6.5 & -2.12 & $3.48 \mathrm{E}+06$ & 0.066 & \\
\hline 383.3052 & $0(\mathrm{o})$ & 7.5 & $26081(\mathrm{e})$ & 7.5 & -0.76 & $7.84 \mathrm{E}+07$ & -0.380 & $B$ \\
\hline 386.3642 & 5439 (o) & 6.5 & $31314(\mathrm{e})$ & 6.5 & -2.44 & $1.61 \mathrm{E}+06$ & -0.107 & \\
\hline 386.7126 & $10770(\mathrm{o})$ & 4.5 & $36622(\mathrm{e})$ & 3.5 & -1.75 & $8.01 \mathrm{E}+06$ & 0.151 & \\
\hline 386.9259 & $10770(\mathrm{o})$ & 4.5 & $36608(\mathrm{e})$ & 5.5 & -1.95 & $5.04 \mathrm{E}+06$ & -0.067 & \\
\hline 388.4546 & 16891 (o) & 5.5 & 42627 (e) & 6.5 & -1.98 & $4.58 \mathrm{E}+06$ & -0.130 & \\
\hline 388.8180 & 5439 (о) & 6.5 & $31150(\mathrm{e})$ & 7.5 & -1.59 & $1.14 \mathrm{E}+07$ & -0.183 & \\
\hline 389.0065 & $0(\mathrm{o})$ & 7.5 & 25699 (e) & 6.5 & -1.41 & $1.71 \mathrm{E}+07$ & -0.181 & $B$ \\
\hline 391.1599 & $0(\mathrm{o})$ & 7.5 & $25558(\mathrm{e})$ & 8.5 & -1.42 & $1.66 \mathrm{E}+07$ & -0.426 & $B$ \\
\hline 393.2425 & $8645(\mathrm{o})$ & 5.5 & 34067 (e) & 6.5 & -1.96 & $4.72 \mathrm{E}+06$ & -0.100 & \\
\hline 394.3565 & 13329 (о) & 4.5 & $38680(\mathrm{e})$ & 3.5 & -1.77 & $7.36 \mathrm{E}+06$ & 0.127 & \\
\hline 396.6400 & 16891 (o) & 5.5 & 42096 (e) & 5.5 & -2.23 & $2.53 \mathrm{E}+06$ & 0.041 & \\
\hline 397.0331 & 5439 (о) & 6.5 & $30618(\mathrm{e})$ & 5.5 & -2.28 & $2.18 \mathrm{E}+06$ & -0.061 & \\
\hline 398.1908 & $10770(\mathrm{o})$ & 4.5 & 35877 (e) & 5.5 & -2.26 & $2.36 \mathrm{E}+06$ & 0.114 & \\
\hline 399.0495 & 10770 (о) & 4.5 & 35823 (e) & 4.5 & -1.04 & $3.85 \mathrm{E}+07$ & 0.232 & \\
\hline 399.8924 & 8645 (o) & 5.5 & $33644(\mathrm{e})$ & 5.5 & -2.27 & $2.20 \mathrm{E}+06$ & -0.094 & \\
\hline 400.4445 & $8645(\mathrm{o})$ & 5.5 & $33610(\mathrm{e})$ & 4.5 & -2.42 & $1.57 \mathrm{E}+06$ & 0.085 & \\
\hline 408.0136 & 8645 (o) & 5.5 & 33147 (e) & 4.5 & -1.94 & $4.58 \mathrm{E}+06$ & 0.138 & \\
\hline 409.1603 & $10770(\mathrm{o})$ & 4.5 & $35204(\mathrm{e})$ & 5.5 & -1.88 & $5.24 \mathrm{E}+06$ & 0.132 & $B$ \\
\hline 409.4415 & 13329 (o) & 4.5 & $37746(\mathrm{e})$ & 4.5 & -2.26 & $2.15 \mathrm{E}+06$ & 0.031 & \\
\hline 421.3947 & 5439 (o) & 6.5 & $29163(\mathrm{e})$ & 7.5 & -2.05 & $3.33 \mathrm{E}+06$ & -0.146 & \\
\hline 421.7413 & 8645 (o) & 5.5 & 32349 (e) & 5.5 & -1.08 & $3.13 \mathrm{E}+07$ & 0.224 & $B$ \\
\hline 426.7066 & 5439 (о) & 6.5 & 28867 (e) & 6.5 & -1.44 & $1.31 \mathrm{E}+07$ & -0.205 & \\
\hline 427.7647 & 5439 (о) & 6.5 & 28809 (e) & 5.5 & -1.66 & $8.07 \mathrm{E}+06$ & 0.163 & \\
\hline 429.8300 & 8645 (o) & 5.5 & $31903(\mathrm{e})$ & 6.5 & -1.57 & $9.54 \mathrm{E}+06$ & 0.207 & $B$ \\
\hline 441.6136 & $0(\mathrm{o})$ & 7.5 & $22638(\mathrm{e})$ & 7.5 & -1.55 & $9.63 \mathrm{E}+06$ & -0.472 & $B$ \\
\hline 444.3778 & 16891 (o) & 5.5 & $39388(\mathrm{e})$ & 6.5 & -2.36 & $1.46 \mathrm{E}+06$ & 0.035 & \\
\hline 444.4493 & 13329 (o) & 4.5 & $35823(\mathrm{e})$ & 4.5 & -1.77 & $5.73 \mathrm{E}+06$ & -0.097 & \\
\hline 444.8104 & $5439(\mathrm{o})$ & 6.5 & $27914(\mathrm{e})$ & 6.5 & -1.18 & $2.28 \mathrm{E}+07$ & 0.365 & $B$ \\
\hline
\end{tabular}


Table 3. continued.

\begin{tabular}{|c|c|c|c|c|c|c|c|c|}
\hline \multicolumn{9}{|c|}{ Levels $\left(\mathrm{cm}^{-1}\right)^{a}$} \\
\hline$\lambda(\mathrm{nm})$ & Lower & $J$ & Upper & $J$ & $\log g f^{b}$ & $g A^{b}$ & $\mathrm{CF}^{*}$ & Note \\
\hline 446.7768 & 10770 (о) & 4.5 & 33147 (e) & 4.5 & -2.28 & $1.75 \mathrm{E}+06$ & -0.109 & \\
\hline 449.4523 & $0(\mathrm{o})$ & 7.5 & $22243(\mathrm{e})$ & 8.5 & -1.36 & $1.45 \mathrm{E}+07$ & -0.449 & $B$ \\
\hline 454.9634 & 8645 (o) & 5.5 & $30618(\mathrm{e})$ & 5.5 & -2.13 & $2.33 \mathrm{E}+06$ & -0.057 & \\
\hline 457.0277 & 13329 (о) & 4.5 & 35204 (e) & 5.5 & -1.99 & $3.24 \mathrm{E}+06$ & -0.151 & \\
\hline 462.0662 & 5439 (о) & 6.5 & 27074 (e) & 7.5 & -1.44 & $1.13 \mathrm{E}+07$ & 0.474 & $B$ \\
\hline 463.2895 & 10770 (о) & 4.5 & 32349 (e) & 5.5 & -1.85 & $4.47 \mathrm{E}+06$ & -0.258 & \\
\hline 479.3710 & 16891 (о) & 5.5 & 37746 (e) & 4.5 & -2.50 & $8.94 \mathrm{E}+05$ & 0.026 & \\
\hline 493.4927 & 19375 (о) & 2.5 & 39633 (e) & 2.5 & -2.23 & $1.63 \mathrm{E}+06$ & -0.125 & \\
\hline 495.7778 & 8645 (o) & 5.5 & 28809 (e) & 5.5 & -2.10 & $2.14 \mathrm{E}+06$ & -0.116 & \\
\hline 499.2637 & 19375 (о) & 2.5 & 39399 (e) & 2.5 & -2.30 & $1.34 \mathrm{E}+06$ & -0.198 & \\
\hline 502.9381 & 17868 (o) & 3.5 & 37746 (e) & 4.5 & -2.25 & $1.48 \mathrm{E}+06$ & -0.192 & \\
\hline 517.8649 & 19375 (o) & 2.5 & $38680(\mathrm{e})$ & 3.5 & -1.63 & $5.98 \mathrm{E}+06$ & -0.372 & \\
\hline 518.8206 & 8645 (o) & 5.5 & $27914(\mathrm{e})$ & 6.5 & -1.81 & $3.92 \mathrm{E}+06$ & -0.306 & \\
\hline 533.0812 & 17868 (о) & 3.5 & 36622 (e) & 3.5 & -2.05 & $2.11 \mathrm{E}+06$ & -0.141 & \\
\hline 554.2039 & 10770 (о) & 4.5 & 28809 (e) & 5.5 & -2.04 & $2.01 \mathrm{E}+06$ & -0.184 & \\
\hline 554.3726 & $0(\mathrm{o})$ & 7.5 & $18033(\mathrm{e})$ & 7.5 & -2.36 & $9.63 \mathrm{E}+05$ & 0.039 & \\
\hline 556.8091 & 10770 (о) & 4.5 & 28725 (e) & 5.5 & -2.12 & $1.62 \mathrm{E}+06$ & -0.194 & \\
\hline 556.8107 & 17868 (о) & 3.5 & 35823 (e) & 4.5 & -1.99 & $2.24 \mathrm{E}+06$ & -0.237 & \\
\hline 579.6590 & 19375 (о) & 2.5 & 36622 (e) & 3.5 & -1.35 & $8.98 \mathrm{E}+06$ & -0.279 & \\
\hline 581.2565 & 5439 (о) & 6.5 & 22638 (e) & 7.5 & -2.71 & $3.82 \mathrm{E}+05$ & 0.084 & \\
\hline 588.3294 & 5439 (о) & 6.5 & 22431 (e) & 6.5 & -2.22 & $1.16 \mathrm{E}+06$ & -0.084 & \\
\hline 596.7409 & 16891 (о) & 5.5 & $33644(\mathrm{e})$ & 5.5 & -2.23 & $1.07 \mathrm{E}+06$ & 0.087 & \\
\hline 615.0077 & 16891 (о) & 5.5 & 33147 (e) & 4.5 & -2.45 & $6.26 \mathrm{E}+05$ & -0.065 & \\
\hline 616.6453 & 21534 (о) & 4.5 & $37746(\mathrm{e})$ & 4.5 & -2.38 & $7.17 \mathrm{E}+05$ & -0.023 & \\
\hline 635.0935 & $17868(\mathrm{o})$ & 3.5 & 33610 (e) & 4.5 & -1.38 & $6.98 \mathrm{E}+06$ & -0.321 & \\
\hline 645.8218 & 13329 (о) & 4.5 & 28809 (e) & 5.5 & -1.30 & $8.18 \mathrm{E}+06$ & -0.366 & \\
\hline 646.7384 & 16891 (о) & 5.5 & 32349 (e) & 5.5 & -1.77 & $2.73 \mathrm{E}+06$ & -0.115 & \\
\hline 649.3623 & 13329 (о) & 4.5 & $28725(\mathrm{e})$ & 5.5 & -1.39 & $6.38 \mathrm{E}+06$ & -0.372 & \\
\hline 654.3449 & 17868 (о) & 3.5 & 33147 (e) & 4.5 & -1.57 & $4.30 \mathrm{E}+06$ & -0.293 & \\
\hline 663.2077 & 21534 (о) & 4.5 & 36608 (e) & 5.5 & -2.46 & $5.34 \mathrm{E}+05$ & -0.058 & \\
\hline 665.9561 & 16891 (о) & 5.5 & 31903 (e) & 6.5 & -1.77 & $2.50 \mathrm{E}+06$ & -0.242 & \\
\hline 790.6727 & 13329 (о) & 4.5 & $25973(\mathrm{e})$ & 5.5 & -2.38 & $4.45 \mathrm{E}+05$ & 0.240 & \\
\hline 827.8591 & 21534 (o) & 4.5 & 33610 (e) & 4.5 & -2.44 & $3.50 \mathrm{E}+05$ & -0.058 & \\
\hline 838.8301 & 16891 (о) & 5.5 & 28809 (e) & 5.5 & -2.02 & $9.06 \mathrm{E}+05$ & -0.097 & \\
\hline 844.8128 & 16891 (о) & 5.5 & 28725 (e) & 5.5 & -1.88 & $1.21 \mathrm{E}+06$ & -0.209 & \\
\hline 906.9854 & 16891 (о) & 5.5 & 27914 (e) & 6.5 & -1.71 & $1.62 \mathrm{E}+06$ & -0.208 & \\
\hline 924.3555 & 21534 (о) & 4.5 & 32349 (e) & 5.5 & -2.44 & $2.91 \mathrm{E}+05$ & -0.072 & \\
\hline
\end{tabular}

a Levels according to the NIST compilation (Martin et al. 1978).

$b \mathrm{HFR}+\mathrm{CP}$ (this work).

* Cancellation factor. Small values indicate large cancellation effects.

B: identified in the spectrum of the CP star HR 465 by Bidelman et al. (1995).

(e) and (o) indicate even and odd parities, respectively.

and $4 \mathrm{f}^{10} 5 \mathrm{~d}, 4 \mathrm{f}^{10} 6 \mathrm{~s}, 4 \mathrm{f}^{10} 7 \mathrm{~s}$ configurations. In addition, we have proceeded to a least-squares fitting of the energy level values (Martin \& Zalubas 1978). The adjusted parameters have been reported elsewhere (Biémont et al. 2001d). For the Slater parameters not varied in the least-squares fit, a scaling factor of 0.85 was introduced (Cowan 1981). The mean deviations reached $48 \mathrm{~cm}^{-1}$ for 50 odd levels and $71 \mathrm{~cm}^{-1}$ for 72 even levels $(0.06 \%$ and $0.16 \%$ of the energy range of the fitted values).
The CP effects were introduced in the calculations according to a procedure described previously (Biémont et al. 1999, 2001a-d; Palmeri et al. 2001; Li et al. 2001). We have adopted for the static dipole polarizability of the core, $\alpha_{\mathrm{d}}$, the numerical value $6.07 \mathrm{a}_{0}^{3}$ (Ho IV) (Fraga et al. 1976) and for the cut-off radius, $r_{\mathrm{c}}$, the calculated HFR result, $r_{\mathrm{c}}=1.47 a_{0}$, which corresponds to the mean value of the outermost $5 \mathrm{p}$ orbital $\left(5 \mathrm{p}^{6}\right.$ core). 
Some difficulties arise, in a general way, when transitions of the type $4 \mathrm{f}-5 \mathrm{~d}$ are considered in RE ions because the $4 \mathrm{f}$ orbitals considerably overlap the $5 \mathrm{~s}$ and $5 \mathrm{p}$ core orbitals. In order to evaluate the $\mathrm{CP}$ effects in an appropriate way, a scaling factor can be applied to the matrix elements of the transitions involving a jump of a $4 \mathrm{f}$ electron. This procedure can replace that consisting in considering a larger number of configurations in the multiconfigurational developments, a procedure which was prevented in the present work essentially by the limits imposed by the computers (very large matrix dimensions). This scaling factor has been deduced semi-empirically from the comparison between theoretical and experimental lifetimes obtained in the present work. In Ho III, the HFR dipole matrix element for the $4 \mathrm{f}^{11}-4 \mathrm{f}^{10} 5 \mathrm{~d}$ transition is $\langle 4 \mathrm{f}|\mathrm{r}| 5 \mathrm{~d}\rangle=1.1487 a_{0}$. We have adopted the value $1.4588 a_{0}$ which corresponds to a scaling factor of 1.27.

The theoretical lifetime results, without (HFR) and with $(\mathrm{HFR}+\mathrm{CP})$ core-polarization effects included in the calculations, are compared in Table 2 with the laser measurements of the present work. For the $4 \mathrm{f}^{10} 5 \mathrm{~d}$ levels, the introduction of the semi-empirical scaling factor on the $<4 \mathrm{f}|\mathrm{r}| 5 \mathrm{~d}>$ transition matrix element involves a lifetime decrease of $36 \%$. The HFR+CP results are in good agreement with the measurements, the discrepancies reaching $11 \%, 11 \%$ and $2 \%$, respectively. There are no other previous theoretical or experimental data for comparison.

The theoretical oscillator strengths and transition probabilities for a sample of $4 \mathrm{f}^{11}-4 \mathrm{f}^{10} 5 \mathrm{~d}$ transitions of astrophysical interest are reported in Table 3 where we give also the cancellation factor, $C F$, for each transition, a small value (e.g. $C F<0.001$ ) of this factor indicating that the corresponding results have to be considered with care. Only the transitions originating from the levels characterized by $E<22000 \mathrm{~cm}^{-1}$ and by $\log g f>-2.50$ appear in the table. A larger set of data (concerning more than 1200 transitions) is available in the database mentioned in the introduction of the present paper.

The Przybylski star contains many lines due to singly ionized RE but the spectrum of HD 101065 contains also many lines of doubly ionized lanthanides. A line of Ho III is observed at $406.508 \mathrm{~nm}$ (see the information available at http://www. astro.lsa.edu/users/cowley/przyb and also Cowley et al. 2000). $\mathrm{Ho}^{2+}$ transitions have been identified in the spectrum of the CP star HR 465 by Bidelman et al. (1995). The identified transitions are indicated by the letter $B$ in the last column of Table 3. All these low excitation transitions are originating from the ground configuration $4 \mathrm{f}^{11}$ and, consequently, are of the type $4 \mathrm{f}-5 \mathrm{~d}$. As we have seen, the $\mathrm{CP}$ effects play a considerable role in this type of transition and, although an adequate scaling factor has been applied to the dipole matrix element, the accuracy of these transitions is expected to be similar to that of the transitions of the other types (i.e. $5 \mathrm{~d}-6 \mathrm{p}$ and $6 \mathrm{~s}-6 \mathrm{p})$. These radiative data are essential for the quantitative analysis of the spectra of CP stars. The assessment of the theoretical modelby the use of the experimental measurements suggests an uncertainty on the oscillator strengths of a few \% for the strong transitions and, in most cases, probably better than $15 \%$.

Acknowledgements. Financial support from the Swedish Natural Science Research Council, from the EU-TMR access to Large-Scale facility programme (contract HPRI-CT-199900041) and from the Belgian FNRS is acknowledged.

\section{References}

Adelman, S. J., Bidelman, W. P., \& Pyper, D. M. 1979, ApJS, 40,371

Aikman, G. C. L., Cowley, C. R., \& Crosswhite, H. M. 1979, ApJ, 232, 812

Bidelman, W. P., Cowley, C. R., \& Iler, A. L. 1995, Wavelength Identification in the Magnetic CP star HR 465 (Publ. Obs. Michigan USA), vol. XII, No. 3

Biémont, E., Li, Z. S., Palmeri, P., \& Quinet, P. 1999, J. Phys. B, At. Mol. Opt. Phys., 32, 3409

Biémont, E., Garnir, H. P., Bastin, T., et al. 2001a, MNRAS, 321,481

Biémont, E., Garnir, H. P., Palmeri, P., et al. 2001b, Phys. Rev. A, 64, 022503

Biémont, E., Garnir, H. P., Li, Z. S., et al. 2001c, J. Phys. B, At. Mol. Opt. Phys., 34, 1869

Biémont, E., Palmeri, P., Quinet, P., et al. 2001d, MNRAS, in press

Blagoev, K. B., \& Komarovskii, V. A. 1994, At. Data Nucl. Data Tables, 56, 1

Blagoev, K. B., Volters, A. K., \& Komarovskii, V. A. 1978, Opt. Spectrosc. (USSR), 45, 932

Bord, D. J., Cowley, C. R., \& Norquist, P. L. 1997, MNRAS, 284,869

Corliss, C. H., \& Bozman, W. R. 1962, Nat. Bur. Stand., Monograph, 53 (US Dept. of Commerce, Washington DC)

Cowan, R. D. 1981, The Theory of Atomic Structure and Spectra (University of California Press, Berkeley, CA, USA)

Cowley, C. R., \& Crosswhite, H. M. 1978, PASP, 90, 108

Cowley, C. R., Ryabchikova, T. A., Kupka, F., et al. 2000, MNRAS, 317, 299

Den Hartog, E. A., Wiese, L. M., \& Lawler, J. E. 1999, JOSA, B16, 2278

Doidge, P. S. 1995a, Spectrochim. Acta, B50, 1421

Doidge, P. S. 1996, Spectrochim. Acta, B51, 375

Fedchak, J. A., Den Hartog, E. A., Lawler, J. E., et al. 2000, ApJ, 542, 1109

Fraga, S., Karwowski, J., \& Saxena, K. M. S. 1976, Handbook of Atomic Data (Elsevier, Amsterdam)

Gorshkov, V. N., \& Komarovskii, V. A. 1979, Opt. Spectrosc. (USSR), 47, 350

Li, Z. S., \& Jiang, Z. K. 1999, Phys. Scr., 60, 414

Li, Z. S., Lundberg, H., Wahlgren, G. M., \& Sikström, C. M. 2000, Phys. Rev. A, 62, 032505

Li, Z. S., Zhang, Z. G., Lokhnygin, V., et al. 2001, J. Phys. B, At. Mol. Opt. Phys., 34, 1349

Martin, W. C., Zalubas, R., \& Hagan, L. 1978, Atomic Energy Levels, The Rare-Earth Elements, Nat. Bur. Stand. Ref. Data Ser. (Washington DC USA), 60

Migdalek, J. 1984, JQSRT, 32, 103

Palmeri, P., Quinet, P., Frémat, Y., Wyart, J.-F., \& Biémont, E. 2001, ApJS, 129, 367 
Ryabchikova, T. A., Davidova, E. S., \& Adelman, S. J. 1990, PASP, 102, 581

Wahlgren, G. M., et al. 2001, submitted

Worm, T., Shi, P., \& Poulsen, O. 1990, Phys. Scr., 42, 569

Wyart, J.-F., \& Palmeri, P. 1998, Phys. Scr., 58, 368

Wyart, J.-F., Blaise, J., Bidelman, W. P., \& Cowley, C. R. 1997, Phys. Scr., 56, 446

Zhang, Z. G., Li, Z. S., Lundberg, H., et al. 2000, J. Phys. B, At. Mol. Opt. Phys., 33, 521
Zhang, Z. G., Svanberg, S., Palmeri, P., Quinet, P., \& Biémont, E. 2001a, A\&A, in press

Zhang, Z. G., Persson, A., Li, Z. S., Svanberg, S., \& Jiang, Z. K. 2001b, Euro. Phys. J. D, 13, 301

Zhang, Z. G., Svanberg, S., Quinet, P., Palmeri, P., \& Biémont, E. 2001c, Phys. Rev. Lett., in press 